\title{
INFLUENCE OF LOADING HISTORY AND BOUNDARY CONDITIONS ON PARAMETERS OF SOIL CONSTITUTIVE MODELS
}

\author{
Magdalena KowALSKA \\ Silesian University of Technology, Faculty of Civil Engineering, \\ Department of Geotechnics, Gliwice.
}

\begin{abstract}
Parameters of soil constitutive models are not constant. This mainly concerns the strain parameters such as $K, G$ or $E_{\text {oed }}$ modules. What influences their values is not only soil type, structure and consistency, but also the history of stress and strain states. So, it is the question of the current state but also of what happened to the subsoil in the past (regarding geological and anthropological activity) and what impact would have the planned soil-structure interaction.

This paper presents an overview of the literature showing how much the soil constitutive model parameters depend on loading and boundary conditions of a particular geotechnical problem. Model calibration methods are shortly described with special attention paid to the author's "Loading Path Method", which allows estimation of optimum parameter values of any soil constitutive model. An example of the use of this method to estimate strain parameters $E$ and $v$ of Coulomb-Mohr elasticperfectly plastic model is given.
\end{abstract}

\section{INTRODUCTION}

Parameters, such as $c, \phi, E_{\text {oed }}$ and others, should not be treated as constants dependent only on soil type and state, even though it was an approach sanctioned by the Polish Standard PN-81/B-03020 [60] - valid till 2010. Most of the soil constitutive model parameters do not constitute universal physical magnitudes. They are rather coefficients, quantitatively describing "stress-strain" relations encoded in a given model $[41,43]$. Results of laboratory and in situ tests show that, if the best prediction of soil behaviour under loading is what we care for - still being the purpose of geotechnical design with the use of theoretical models, distribution of soil parameter values should be taken as three-dimensional, dependent not only on subsoil profile and material characteristics of the particular layers, but also on the loading history at the analysed point. The loading history consists of: geological and anthropogenic processes influencing initial conditions in the soil layer being analysed (e.g., structure and preconsolidation), position in relation to the current source of loading, its magnitude and changes with time. At each point of subsoil it can be reflected as a loading path (with its length and shape) in the stress or strain space.

The range of changeability of parameter values depends directly on quality, or in other words - advancement, of the constitutive model that the parameters belong to. The less the theoretical soil response (simulated based on the theoretical model equa- 
tions) with the use of constant soil parameters differs from the real observed (measured) soil behaviour, the "better" the model is. Unfortunately, there is still a long way to go before such a model is created, that with a limited number of constant parameters would perfectly simulate any possible soil reaction to loading. Till then, analyses have to be confined to simpler, accessible and easier in application models and optimization of their predictions may be searched for by making the parameters variable. This is why the Loading Path Method (LPM) [23, 39, 40, 42] was created. Its detailed description may be found in the author's doctoral thesis [41].

In Section 2 of this paper, based on the current state of knowledge, evidence of the huge changeability of the most common soil constitutive model parameters and their dependence on loading history and boundary conditions of a particular problem will be presented. Chapter 3 will throw light on the place of the LPM among the other methods of parametrical identification of soil constitutive models. Eventually, an example of the use of the LPM for estimation of optimal parameter values of elasticperfectly plastic model with Coulomb-Mohr failure condition will be presented. It will concern the probably simplest geotechnical problem, which is a pad foundation on a homogeneous soil.

\section{VARIABILITY OF PARAMETERS IN THE LIGHT OF CURRENT RESEARCH}

The most visible and probably the best documented in literature is changeability of shear $G$ and uniaxial strain $E$ moduli. Their values decrease with shear or axial strain and simultaneously (in the case of sedimentary soils) increase with effective mean stress. They depend also on other factors, briefly described below, which generally is in contradiction with the assumption of linear elasticity of soil - describable with just one constant value of stiffness modulus. Thus estimation of this most popular parameter (used under different forms in almost every soil constitutive model) becomes not in the least trivial.

The increase of soil stiffness with depth - dependent directly on the effective initial vertical stress $\sigma_{v 0}^{\prime}$ in subsoil, is distinctly observed in field tests, e.g., with the use of continuous surface wave techniques [57] or in CPT tests [61, 77]. This fact was for the first time taken into account in numerical modelling by Gibson [20] in 1967, who presented the initial shear modulus $G_{0}$ as a linear function of depth. At that time this was the simplest but highly important improvement of the linear elastic soil model. The initial stiffness modulus is influenced also by the coefficient of earth pressure at rest $K_{0}$, which is not constant either. Its value depends on soil state (e.g., in the case of loose sands it increases with void ratio $e$ [10]) and overconsolidation ratio $O C R$. So, indirectly, the $G_{0}$ modulus is affected by the geological history of subsoil. 
Already in 1964, Ladd [44] stated that the value of Young modulus $E$, when assessed based on undrained triaxial tests, depends on the level of applied shear stress, OCR, the effects of time (thixotropy, aging and rate of strain), direction of the major principal stresses and the magnitude of intermediate principal stress. Its strong dependence on mean effective stress $p^{\prime}$ and, connected with it, void ratio $e$ was proved also, e.g., in the work of Kawaguchi et al. [38] on the basis of standard triaxial drained and undrained tests carried out on reconstituted clays. Młynarek et al. [53], based on research of Hardin [28], Jamiolkowski et al. [30], Schnaid [66] and Młynarek et al. [54], formulated an equation specifying variation of the initial maximum shear modulus $G_{0}$ for sands

$$
G_{0}=f\left(\sigma_{v 0}^{\prime}, e_{0}, O C R, S_{r}, C, K, T, I_{o m}, d d\right)
$$

where:

$e_{0}-$ initial void ratio,

$S_{r}-$ degree of saturation,

$C$ - grain characteristics,

$K$ - soil structure,

$T$ - temperature,

$I_{o m}-$ content of organic matter,

$d d$ - degree of decay (for alluvial soils).

The strong nonlinearity of shearing and dilatancy characteristics was the subject of study of many research centres. The decrease of soil stiffness in the range of large shear or axial strains is a phenomenon, observed in each shearing test of soil specimen (e.g., [69]), which has long been taken into account in geotechnical analyses [16, 18]. But a relatively new achievement (the 70's of the 20th century) is perceiving of soil nonlinearity in small strain range $\left(10^{-3}\right.$ and less), where for long stiffness moduli were assumed to be constant. There was even a concept of dynamic modulus [27] created, which was erroneously thought to be another soil strain characteristic relating to cyclic-dynamic loading. Not until complementary system for strain measurements, i.e., "bender" elements, resonant columns and local displacement sensors in laboratory tests and seismic cones in field tests, plus, previously used, global strain measurement methods, was put into practice, the phenomenon of the rapid decrease of stiffness in small strain range was discovered. Only then it became possible to connect the two concepts: static and dynamic moduli into one common characteristic of stiffness variability for the whole range of strain. The greatest contributions into propagation of this knowledge belong to Jardine et al. [31-33], Burland [8], Jardine [34], Smith et al. [70]. As far as the Polish research is concerned, it is worth mentioning the works by Jastrzębska [35] (cohesive soils) and Świdziński [74] (noncohesive soils).

The "nonlinearity of small strain", next to "critical state" and Terzaghi's "effective stress", is now a fundamental concept of soil mechanics. Practically, every contemporary soil constitutive model to be called advanced must take these three concepts into account (e.g., "bubble" model 1; 3SKH model by Stallebrass and Taylor [72]; non- 
linear model by Puzrin and Burland [62], Bounding Surface Soil Plasticity [15] or NAHOS [22]).

On the occasion of researching the influence of strain on Young modulus, Burland [8] noticed that the modulus is strongly dependent on the analysed boundary value problem. Based on some numerical analyses and triaxial tests carried out by Jardine et al. [32], the author stated that the variability of the apparent secant modulus $E$, normalised against the undrained soil strength $c_{u}$, in undrained triaxial test approximates well behaviour of a pad foundation and a strutted excavation. But the moduli were much too high for a cavity expansion case and too small for a stiff pile. This constitutes the evidence of the fact that an optimal model calibration should be always done with reference to the geotechnical problem being analysed.

The research conducted hitherto into the influence of loading history on soil behaviour included, e.g., comparisons of soil response to stress paths with a common beginning and end, but different intermediate course. Gryczmański [26], on the basis of experiments on Lagunillas clay conducted by Lambe [46], analysed a specimen loaded according to a standard total stress path but with different boundary conditions, namely with slow loading (drained) and fast loading (undrained), the latter ended with consolidation. The soil response was definitely different, not only quantitatively but also qualitatively, so an attempt to estimate shear modulus value in such a case would give different results depending on the test conditions.

Similar experiments with the use of sands were carried out by Drescher and Bojanowski [17], Tatsuoka and Ishihara [75], Lade and Duncan [45], Yasin and Tatsuoka [82]. Tatsuoka and Ishihara demonstrated that if loading paths between two points have different shape with unloading and reloading at high levels of stress, the end values of strain are very different and so are material characteristics and parameters. Shear strain dependence on stress path was also proved by Moroto [56], Kamegai [37], Yasin and Tatsuoka [82].

In research on influence of loading path shape on soil behaviour there is often a bunch of radial stress paths with the same starting point used. Thanks to this kind of tests, e.g., Graham et al. [21] and Atkinson et al. [3] showed how shear $G$ and bulk $K$ moduli depend on the direction of stress paths. Atkinson [4] and Atkinson et al. [3] proved that in the case of preconsolidated cohesive soils a rapid $\left(>90^{\circ}\right)$ change in stress path direction has an enormous influence on the value of initial stiffness modulus and that this dependence weakens when strain becomes greater than $0.5 \%$. Jardine [34] separated three surfaces (yield, history, bounding) in the stress space, which isolate different types of mechanical soil response (linear elastic, hysteretic, plastic). Within the zones different constitutive relations and different parameters may be applied. Analogous results were presented by Smith et al. [70] in reference to Bothkennar clay. This soil property was used, for example, in the 3SKH model by Stallebrass and Taylor [72] or in the model by McDowell and Hau [51]. 
Triaxial tests carried out by Bjerrum and Lo [5] gave evidence to a strong dependence of the initial value of Young modulus on the length of secondary consolidation (creep) before undrained shearing. The $E_{0}$ value was even ten times greater when the consolidation period lasted 60 days when compared to one day. Similar results were obtained by Som [71], who noticed that the compressibility of London clay samples in oedometer test was considerably reduced (i.e., the stiffness was increased) following an extended period when the loading was maintained constant.

On the basis of tests published by Henkel and Sowa [29], Yasin and Tatsuoka [82] observed that for cohesive soil specimens with the same initial void ratio at the same initial stress state, the void ratio at a given later stress state will be larger when that stress state is reached, with continuous yielding, by tracing stress paths closer to the failure envelope, e.g., radial $K_{0}$ consolidation versus isotropic consolidation followed by drained shearing. These results suggest that plastic volumetric strain is smaller if the stress path runs closer to the bounding (failure) surface. This refutes the Rendulic's hypothesis [63] that there exists a straightforward dependence between the effective stress and the moisture content. Volumetric plastic strain is thus dependent on stress path shape. Other researchers, e.g., Lewin and Burland [49], LeLievre and Wang [47], Gens [19] and Tatsuoka et al. [76], came to similar conclusions. This casts doubt on the critical state theory assumption of treating plastic volumetric strain as an independent hardening parameter.

Not all constitutive models make use of parameters $E, K$ or $G$. Critical state models, for example, operate on parameters $\lambda$ and $\kappa$ to describe soil deformation. Parameter $\kappa$ in the Modified Cam Clay model (MCC) [64] refers to elastic strain within the yield surface, so all the comments above concerning elastic moduli apply to it. Whereas parameter $\lambda$ refers to the elastic-plastic strain and its value, according to the definition, is obtained based on the $e-\ln \left(p^{\prime}\right)$ graph, as a slope of an approximation line representing void ratio change due to isotropic stress path or any other radial stress path beginning at the centre of $p^{\prime}-q$ invariants space. Newland [59] and Yudhbir et al. [83] proved that $\lambda$ is not constant either and its value decreases as $q / p^{\prime}$ grows. Thus magnitude of $\lambda$ estimated on the basis of an isotropic compression in triaxial test may be different from the one identified by an oedometric test. The differences in $\lambda$ values for various radial stress paths may reach even $20 \%$. The assumption of rectilinearity of $e-$ $\ln \left(p^{\prime}\right)$ graph in the case of highly compressible soils turns out to be untrue either. This proves dependence of $\lambda$ and $\kappa$ on the mean effective stress. This phenomenon has been elucidated by Butterfield [9], who suggested to replace $\lambda$ and $\kappa$ with $\lambda^{*}$ and $\kappa^{*}$, obtained on the basis of an $\ln (e)-\ln \left(p^{\prime}\right)$ diagram instead of $e-\ln \left(p^{\prime}\right)$. Such a modification was used, e.g., in the "bubble" model by Al-Tabbaa [2].

As far as the loading history influence on soil behaviour is concerned, geological history, expressed by $O C R$, and soil formation processes responsible for soil structure should be mentioned again. The great majority of the theoretical soil constitutive 
models have been created based on remoulded laboratory samples. Research conducted by Leroueil and Vaughan [48] showed however that many natural soils demonstrate such strength and stiffness that are difficult to simulate in laboratory conditions. Thus soil structure is as important as the initial porosity or the loading history. To differentiate the parameter values estimated on the basis of laboratory tests on remoulded soils (reconstituted at a water content of between $w_{L}$ and $1.5 w_{L}$ ) from the natural soils' parameters, Burland [7] called them intrinsic. The subject of soil structure was undertaken by, among others, Maccarini [50], Cotecchia [13], Cotecchia and Chandler [12], Shibuya [68], Mitchell and Soga [52], Sukolrat [73]. As an example, results of Maccarini's [50] tests may be given. The author proved that, in contrast to sedimentary soils, stiffness of loose residual soils (and other cemented materials) in a standard triaxial test decreases as the confining stress increases over the so called first bond yield. This happens as a result of a gradual breaking of the inter-particle bonds, which in residual soils are still present, even though much weaker than in the parent rock. In direct shear tests, on the other hand, the same soils behave similarly to sedimentary soils. The difference, in Maccarini's opinion, seems to be related to the different stress paths followed by the two tests.

Not all constitutive model parameters are equally sensitive to the loading history. For example, Yasin and Tatsuoka [82] showed that, within the limit of stress range covered in their study, the stress history had no significant effect on both the peak and residual angle of internal friction of Toyoura sand. Similar results for Weald clay were provided by Henkel and Sowa [29]. This does not mean, however, that the internal angle of friction or, corresponding, critical state parameter $M$ are constant for one soil. The Mohr failure envelope's shape resembles a parabola [81], which is commonly observed in experiments on rocks [65]. Confirmation of this thesis may be found in the tests of intact Todi Clay and London Clay presented by Burland [7], or reconstituted Boom clay (Belgian marine clay) published by Coop et al. [11] or Bouazza et al. [6]. They showed that the inclination of the critical line $M$ decreases at high values of effective mean stress and so would the angle of internal friction $\phi^{\prime}$. The size of the failure surface depends also on the soil structure - it is greater in the case of natural (structured) soils when compared to reconstituted soils. This was proved, e.g., by the results of experiments carried out on Todi Clay, presented in the above mentioned work of Burland [7]. As far as the influence of boundary conditions on the shape of failure surface and parameters describing it is considered, Jefferies and Shuttle [36] and Wanatowski and Chu $[79,80]$ in their studies of noncohesive soils proved that the aforementioned parameter $M$ takes smaller values in plain strain compression than in triaxial conditions. This means that $M$ value is affected by the intermediate principal stress.

All the examples presented above document well that estimation of mechanical soil parameters should always be done with consideration of the test conditions adequate to the geotechnical problem analysed. Especially, at the third geotechnical category, 
when complex soil conditions and untypical highly important structures are dealt with, typical oedometric tests or standard triaxial shearing may not be enough for optimal evaluation of parameter values of the chosen constitutive model. By "optimal" such values are meant that would provide the best fitting of the theoretical soil response to the one observed in situ during construction and exploitation of the given soil/structure system.

\section{PROCEDURES OF SOIL CONSTITUTIVE MODELS' CALIBRATION}

A parametric identification of a soil constitutive model is in general a nonlinear regression problem, where parameters are the regression coefficients. This is because soil (always multiphase and inhomogeneous) is a stochastic material. An evidence to this may be simply the fact that test results, no matter whether conducted in laboratory or in situ, at all times present some scatter, even if identical loading procedures are followed.

Estimation of parameters of any soil constitutive model demands at the beginning establishing a set of state variables (settlement, strain, etc.) and a method of building the data base of the information observed. Based on these assumptions and dependent on the case analysed, according to Gryczmański [24], the identification problem may be called either a local calibration or a global calibration issue.

The global calibration consists in comparison of theoretical data (e.g., in the form of settlements and/or structure inclinations, excess pore pressure values, internal structure forces, etc.) with the results obtained from calibration chamber tests, in situ experiments or monitoring of already existing structures. Estimation of parameters is done in inhomogeneous state of stress and strain conditions. The subsoil may be treated as one body without differentiating any points or layers. The biggest advantage of global calibration is the possibility of analysis of real soil conditions without the necessity of sampling and disturbance of subsoil structure. While the greatest disadvantage is the problem of scale: often the loading zone is much smaller in the experiment than in the designed soil-structure interaction issue. There often exist also limitations on the loading methods (magnitude, direction, time). All this may make reliability of the parameter estimation questionable.

The local calibration is carried out at the level of isolated surroundings of chosen points in subsoil in conditions of controlled and uniform states of stress and strain. This is why this method is much more popular in theoretical analyses. Data, in the form of magnitudes representing state of stress or strain, are most of the times obtained in the way of conventional laboratory tests, where each parameter is evaluated separately. A wide spectrum of loading paths or representative loading paths can be used as well. More than one parameter (or even all of them) may be then estimated during one comparison run. In this kind of calibration there also exists the problem of 
scale (especially in the case of coarse soils), but it is seen from a different point of view (material homogeneity). The basic disadvantage of this method is examination of soil in the form of a specimen of limited size, isolated from a real subsoil, swelled and most often with changed structure.

In the author's opinion, among the local calibration methods listed, special attention should be paid to the representative loading paths version, the example of which is the Loading Path Method mentioned. As the only one from the local calibration techniques, it takes loading history and boundary conditions of the analysed geotechnical problem into account. This makes it closest to the global calibration methods, maintainig at the same time all the merits of local calibration. In brief, the optimal estimation of model parameters in LPM is based on the best possible fitting of the theoretical response path to the experimental response path. The latter is obtained as a result of a properly planned laboratory test on a sample of soil taken from the representative point of subsoil. Its structure should be possibly undisturbed or, ultimately, reconstituted. The sample is loaded in such a way to simulate the loading path, which, according to the predictions and the calibrated (or better) constitutive model, would occur at the given point of subsoil.

\section{EXAMPLE OF THE USE OF LPM}

One of the most commonly used in practical issues is the elastic-perfectly plastic model with the failure condition of Coulomb-Mohr (CM, for short) $[14,55]$. It operates on four parameters only. Two of them, often called "strain parameters": Young modulus $E$ and Poissons ratio $v$, describe soil behaviour within the range of exploitation loads (before failure), where in CM model linear elasticity applies. Two other, called "strength parameters": cohesion $c^{\prime}$ and angle of internal friction $\phi^{\prime}$, define the failure envelope. The "strain" and "strength" parameters, just like the equations in which they are used, are independent and, according to the definition, may be estimated separately. This means that if local calibration of CM model at such points of subsoil where failure was not achieved is under consideration, evaluation of $c^{\prime}$ and $\phi^{\prime}$ values is impossible (and unnecessary!), because they do not exist in the constitutive relations describing soil behaviour within the failure surface. In such a case the CM model is reduced to the linear elastic model. The only possible is, in a separate analysis, determination of a combination of the minimal "strength parameters" values, for which the failure state at the given stress paths would not be achieved.

This chapter presents a comparison of CM parameters of a uniform cohesive soil loaded by a simple pad foundation obtained in a classical way (based on separate standard tests) and with the use of LPM (optimal values). 


\subsection{SOIL SAMPLES AND "CLASSICAL” PARAMETER VALUES}

Kaolin Speswhite was chosen for the analysis, as one of the most often used in element tests. With regard to grading, according to Eurocode 7, it may be identified as Clay $\left(\mathrm{f}_{\mathrm{cl}}=80 \%, \mathrm{f}_{\mathrm{si}}=20 \%\right)$. Laboratory samples were prepared from a homogeneous paste with water content corresponding to $1.3 w_{L}$, thanks to which the parameters obtained in laboratory tests might be called intrinsic. The material consolidated under $150 \mathrm{kPa}$ vertical load, providing enough strength to be handheld and prepared for triaxial tests. Before the actual triaxial test the specimens achieved a physical state characterized by liquidity index $I_{L}=0.5$.

According to the method B of the Polish Standard PN-81/B-03020, that is, on the basis of the soil type and state only, such a soil could be described with the following parameter values: $E=8.75 \mathrm{MPa}, v=0.37, c_{u}^{(n)}=35 \mathrm{kPa}, \phi_{u}^{(n)}=6.5^{\circ}$. Whereas parameters obtained as results of standard strength and deformation laboratory tests (own and derived from literature) were estimated as $E_{0.5 q f}=20.5 \mathrm{MPa}$ (based on secant shear modulus $G$ in shearing with constant $p^{\prime}=200 \mathrm{kPa}$ ), $v=0.33, c^{\prime}=0 \mathrm{kPa}$ (newly remoulded soil [67]), $\phi^{\prime}=20-25^{\circ}$.

\subsection{NUMERICAL MODEL AND LOADING PATHS}

A cuboid footing of dimensions: $1.2 / 1.8 / 0.6 \mathrm{~m}$, founded at a depth of $1.5 \mathrm{~m}$ was modelled in Z_Soil.PC 2007 v.7.38 FEM program as linearly elastic with parameters: $E=27.5 \mathrm{GPa}, v=0.2, \gamma=25 \mathrm{kN} / \mathrm{m}^{3}, e_{0}=0$. The subsoil was assumed as uniform described with Modified Cam Clay model with van Eekelen's correction [78] and parameters corresponding to Speswhite kaolin: $M=0.9, \lambda=0.21, \kappa=0,02, e_{0}=1.4$, $v=0.3, \gamma=16.6 \mathrm{kN} / \mathrm{m}^{3}, K_{0}=0.64$. This constitutive model was chosen as the most advanced of all the material models available in the program, assuming that this would guarantee obtaining loading paths more reliable (closer to reality) than with the use of CM model. The loading process was divided into 3 stages: (1) accumulation and erosion (120 kPa providing achievement of the $150 \mathrm{kPa}$ required during preparation of samples), (2) excavation and construction of the footing, (3) exploitation load of the footing $(500 \mathrm{kPa})$. There were 7 finite elements chosen for analysis as representative points of the subsoil. They are presented in Fig. 1.

It was decided that loading in LPM would be presented as changes in the stress state - in form of invariants: $p^{\prime}-q-\theta$, which denote: mean effective stress $p^{\prime}$, equivalent stress $q$ and Lode's angle $\theta$. It was assumed that $q$ would take negative sign always where Lode's angle value $\theta$ is greater than $0^{\circ}$. As can be seen in Fig. 1, only the stress path of element A achieved the critical state line (CSL) on the extension side (which in MCC model does not equal failure). State of stress at all points remained in the elastoplastic region and did not achieve failure. All the stress paths analysed started from 
the $K_{0}$ line with inclination corresponding to the given initial value $K_{0}=0.64$. Then they jumped onto the anisotropic consolidation line with inclination of $K=0.78$, the value of which corresponds to the coefficient of earth pressure at rest in uniaxial state of strain, resulting from the constitutive equations of the MCC model [58]. In the unloading (erosion) stage, the stress paths were again characterized by a common inclination, dependent only on the Poisson's coefficient, which applies in the elastic zone - within the yield surface of the MCC model. During the further loading process (the 2nd and 3rd stages) the loading paths became different depending on the analysed point of the subsoil. Yet, one common feature was the characteristic bend of all the stress paths, wherever the stress state crossed the current yield surface, where in the MCC model elasticity transfers into elastoplasticity. There was only one point $D$, where, assessing from the shape of the loading path, the yield surface was not achieved.

(a)

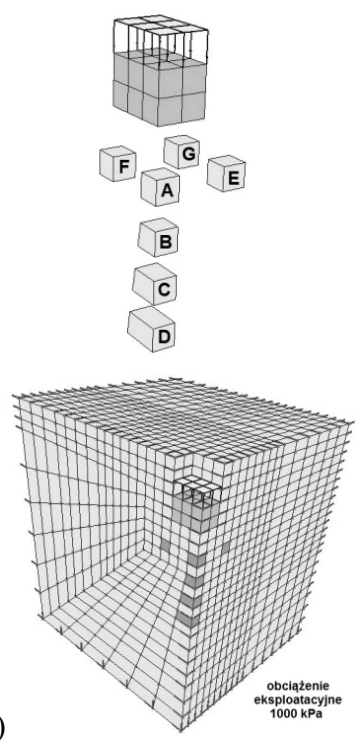

(b)

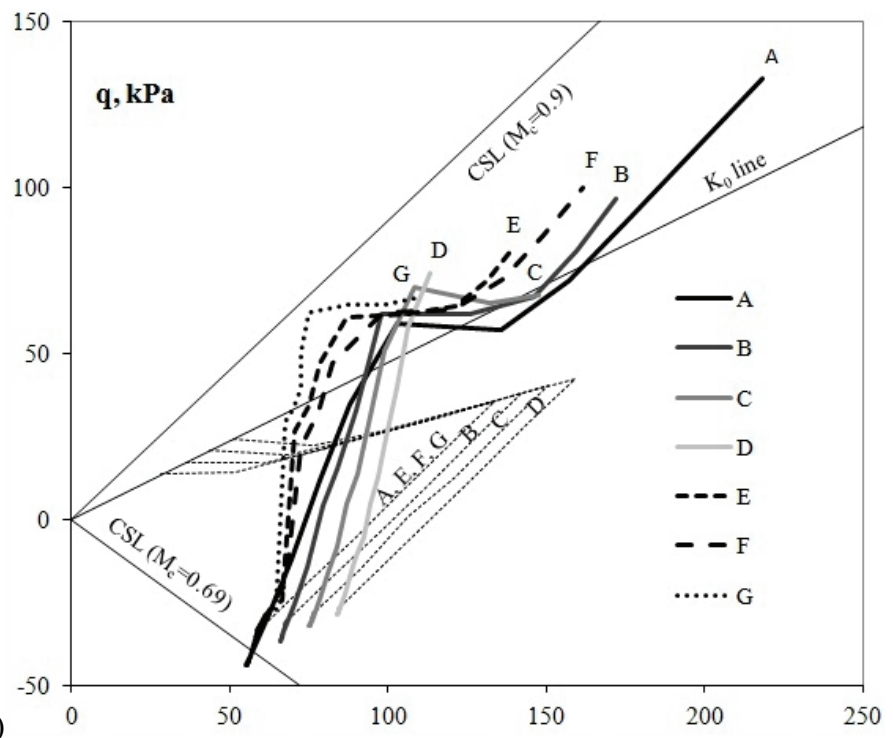

Fig. 1. (a) FEM model of the footing with elements chosen for the analysis;

(b) stress paths at elements $A-G$

\subsection{EXPERIMENTAL RESPONSE PATHS}

Material samples, prepared as was described in 4.1, were loaded tracing the stress paths presented in Fig. 1. Triaxial apparatus equipped with the stress path control system was used. The purpose of using the loading path sections corresponding to the accumulation and erosion (thin dotted lines in Fig. 1) in the triaxial tests was only to provide the common loading history through simulation of the consolidation process, 
necessary to form the hand-handable triaxial specimens. That is why in the optimization algorithm of LPM only this part of the response was used, which corresponded to the 2nd and 3rd stages (bold lines in Fig. 1). Since loading was presented in the form of the $p^{\prime}-q$ stress paths, the matching response paths must have been given as invariants of strain $\varepsilon_{v o l}-\varepsilon_{s}$ (volumetric and shear strain).

Figure 2 shows the experimental response paths for all the specimens and the theoretical response paths obtained with the use of $\mathrm{CM}$ model and parameters from the Polish Standard PN-81/B-03020. It is clearly visible that with this set of parameters the predicted shear strains were 4.5 times smaller and volumetric strains -5 times smaller. Apart from that, the CM model was not able to simulate the curvilinearity of strain paths, even though the general shape of paths seemed similar to the one observed in triaxial test results. The specimen representing element A nearly achieved failure during the initial extension, while according to the CM model that would happen not sooner than in the 3rd stage of loading at stress level $\left(p^{\prime}, q\right)=(207 ; 121) \mathrm{kPa}$.

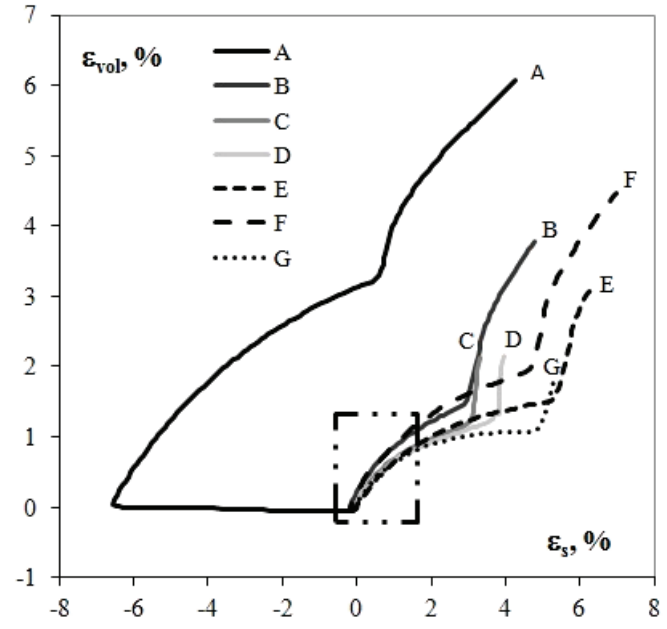

(a)

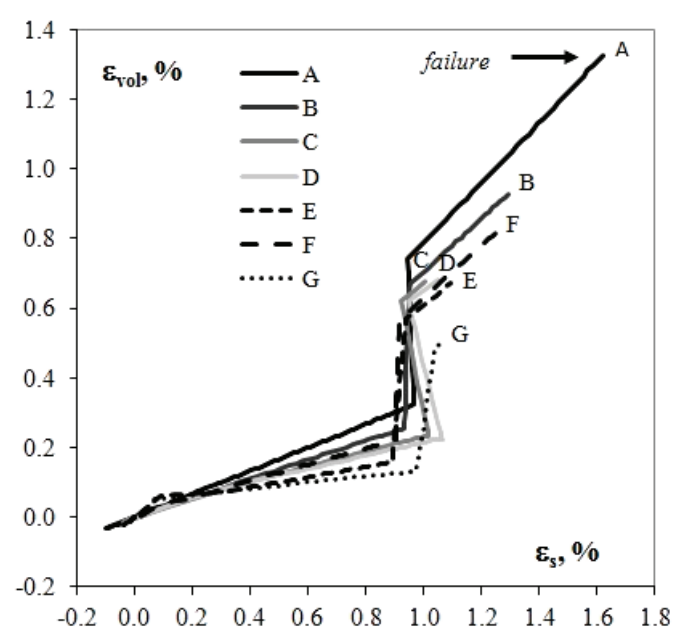

(b)

Fig. 2. (a) Experimental (triaxial) strain paths; range of theoretically predicted strain presented in the rectangle; (b) theoretical strain paths obtained with the use of CM model and parameters from $\mathrm{PN}-81 / \mathrm{B}-03020$

\subsection{OPTIMIZATION RESULTS}

The constitutive equations of the CM model were encoded in MATLAB program together with the optimization procedure, in which a classical genetic algorithm was used [41]. Selection of individuals (possible solutions) was done with the use of a roulette method. For each set of the laboratory results the algorithm was run at least 
three times. In the first run wide ranges of parameter values were used $\left(c^{\prime}=0-50 \mathrm{kPa}\right.$, $\phi^{\prime}=0-60^{\circ}, E=0-20 \mathrm{MPa}$, and $\left.v=0-0.5\right)$, which in the next runs were gradually narrowed around the estimated optimal values. Parameter values were coded as real numbers. The probability of crossover was set at the level of $90-100 \%$ and probability of mutation: $1-5 \%$. Multi-point crossover was used - each gene in the chromosome drawn (one parameter of the set) was changed with the probability of $50 \%$. Elitism rule was applied. In each run 500 individuals in 500 generations were analysed.

It was assumed that "optimal" will be such a set of CM model parameters, for which the theoretical strain path (as the answer to the stress path used in the laboratory test) along its whole length would be fitting to the experimental strain path in the best way. The fitness function equation $S(\boldsymbol{b})$, being therefore a measure of fitting, was based on the least square method with assumption of the same weight applied to volumetric and shear strains

$$
S(\boldsymbol{b})=\frac{\sum_{1}^{n} \sqrt{\left(\frac{\varepsilon_{s . d}-\varepsilon_{s}(\boldsymbol{b})}{\varepsilon_{s . d}^{\max }-\varepsilon_{s . d}^{\min }}\right)^{2}+\left(\frac{\varepsilon_{\text {vol.d }}-\varepsilon_{\text {vol }}(\boldsymbol{b})}{\varepsilon_{\text {vol.d }}^{\max }-\varepsilon_{\text {vol.d }}^{\min }}\right)^{2}}}{n} \rightarrow \min
$$

where:

$n$ - number of readings,

$\varepsilon_{\text {s.d }}, \varepsilon_{\text {vol.d }}$ - shear and volumetric state of strain values - obtained in the laboratory test,

$\varepsilon_{s . d}^{\max }, \varepsilon_{\text {vol.d }}^{\max }, \varepsilon_{s . d}^{\min }, \quad \varepsilon_{\text {vol.d }}^{\max },-$ maximal and minimal values of $\varepsilon_{s . d}$ and $\varepsilon_{\text {vol.d }}$ in one analysed laboratory test,

$\varepsilon_{s}, \varepsilon_{\text {vol }}$ - shear and volumetric state of strain values, obtained on the basis of CM model constitutive equations and the tested set of parameter values $\boldsymbol{b}$ as the answer to the $p^{\prime}-q$ stress path applied in the analysed laboratory test.

This dimensionless function denotes the mean, relative to the whole range of strain measured in the triaxial test, distance between the corresponding states of volumetric and shear strain along the whole length of the response path. It takes values between 0 and 1 . The closer to zero the $S(\boldsymbol{b})$ value is, the better the fitting of the theoretical response path to the experimental one.

Because, de facto, only one of the kaolin samples achieved the state of stress close to failure, estimation of the parameters $c^{\prime}$ and $\phi^{\prime}$ of CM model was not possible, so only parameters $E$ and $v$ could be assessed. Their optimal values, together with the information about position of each analysed point of subsoil ( $z$-depth, $r$ - horizontal distance from the centre of the footing) and fitness function values $S(\boldsymbol{b})^{\mathrm{opt}}$ are listed in Table 1. For contrast, in Table 1 values of the fitness function $S(\boldsymbol{b})^{\mathrm{PN}}$, obtained with the use of the standard parameter values: $E=8.75 \mathrm{MPa}, v=0.37$, are presented, too. In Figure 3, the optimal values of $E$ and $v$ versus depth and distance from the loading 
source are depicted. And in Figure 4, the response paths for each representative point of subsoil are compared: experimental, theoretical with the use of the optimal parameter values and experimental with the use of the parameter values based on the Polish Standard.

Table 1

Optimization results

\begin{tabular}{|c|c|c|c|c|c|c|c|}
\hline & & $z$ & $r$ & $v^{\text {opt }}$ & $E^{\text {opt }}$ & $S(\boldsymbol{b})^{\text {opt }}$ & $S(\boldsymbol{b})^{\mathrm{PN}}$ \\
\hline No. & point & $\mathrm{m}$ & $\mathrm{m}$ & - & $\mathrm{MPa}$ & - & - \\
\hline 1 & $\mathrm{A}$ & 2.25 & 0.21 & 0.13 & 5.3 & $\mathbf{0 . 2 9 4}$ & $\mathbf{0 . 4 8 6}$ \\
\hline 2 & $\mathrm{~B}$ & 2.85 & 0.21 & 0.35 & 2.6 & $\mathbf{0 . 1 1 9}$ & $\mathbf{0 . 4 6 9}$ \\
\hline 3 & $\mathrm{C}$ & 3.45 & 0.21 & 0.29 & 3.6 & $\mathbf{0 . 1 8 3}$ & $\mathbf{0 . 4 5 0}$ \\
\hline 4 & $\mathrm{D}$ & 4.05 & 0.21 & 0.30 & 3.3 & $\mathbf{0 . 2 0 1}$ & $\mathbf{0 . 4 7 5}$ \\
\hline 5 & $\mathrm{E}$ & 2.25 & 1.06 & 0.36 & 1.7 & $\mathbf{0 . 1 8 8}$ & $\mathbf{0 . 5 3 9}$ \\
\hline 6 & $\mathrm{~F}$ & 2.25 & 1.06 & 0.37 & 1.7 & $\mathbf{0 . 1 2 7}$ & $\mathbf{0 . 5 2 7}$ \\
\hline 7 & $\mathrm{G}$ & 2.25 & 1.48 & 0.29 & 2.2 & $\mathbf{0 . 2 0 8}$ & $\mathbf{0 . 5 5 2}$ \\
\hline
\end{tabular}
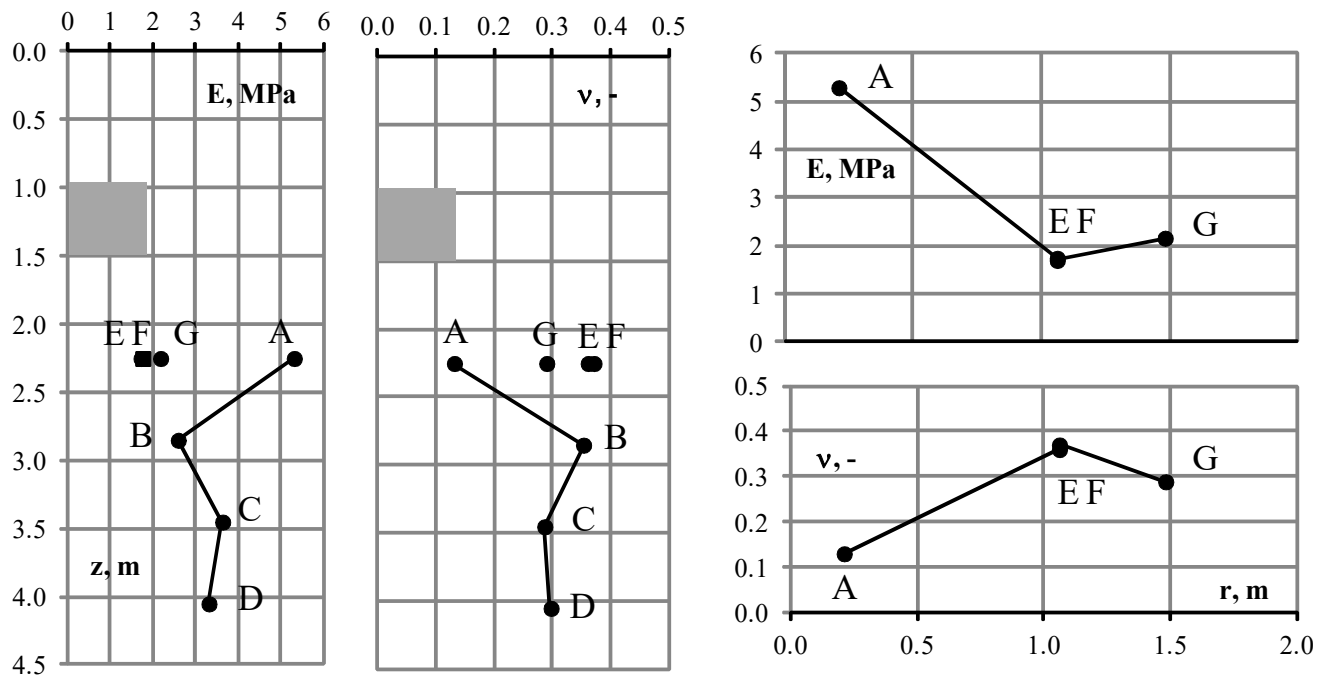

Fig. 3. Optimal values of $E \& v$ depending on depth $(z)$ and distance from the pad foundation $(r)$

It turned out that when the optimal (variable within the subsoil) values of parameters were used, the theoretical prediction of the specimens' deformations was even 4 times closer to the one observed in the laboratory test when compared to the results obtained with the use of the parameter values taken from the Polish Standard. 

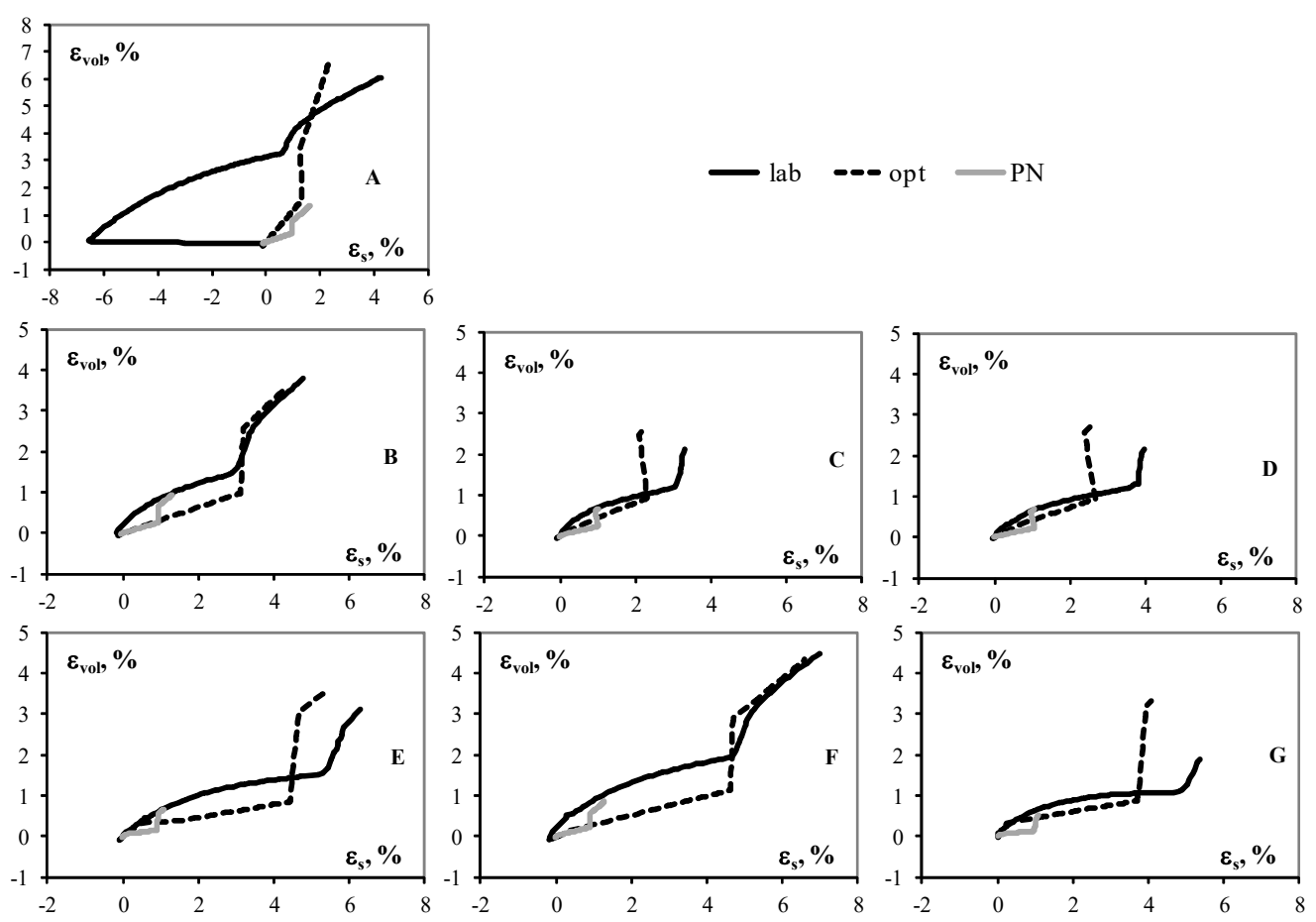

Fig. 4. Comparison of strain paths $\varepsilon_{s}-\varepsilon_{v o l}$ : experimental (lab), theoretical - optimal (opt) and theoretical - obtained on the basis of parameter values from Polish Standard (PN)

The best fitting was achieved in the case of the specimens representing points B and $\mathrm{F}$. With the optimal parameters the differences in predicted final values of shear and volumetric strains were smaller than $0.5 \%$. There was also a good visual match between the theoretical and experimental paths in the final range of strains.

At the points $\mathrm{C}, \mathrm{D}$ and $\mathrm{G}$ the theoretical response paths were closer to the experimental ones in the initial range of strain, but the estimation of the final values of strain was much worse - the obtained differences were even almost $1.5 \%$. However, when compared to the approximations based on the standard values of parameters, for which the discrepancy was about $5 \%$, this result seems acceptable. The worst fitting of the optimal response path was recorded in the case of specimen A. This was due to the very high increase of strain at extension in the pre-failure state, which could not be simulated properly by CM model, even with optimum values of parameters.

If the result of sample A were neglected, it might be stated that the optimal value of the Young modulus for the analysed fragment of subsoil varied between 2 and 3.5 MPa, with a subtle increase with depth. This value was about 3 times smaller than the one suggested in the Polish Standard. Poisson's ratio was smaller than the standard 
value either. It might be assessed at the level of $0.3-0.35$ with the higher value concerning places closer to the foundation.

\section{SUMMARY}

Estimation of soil constitutive model parameters based just on the basic standard field or laboratory tests without any consideration paid to the loading history or boundary conditions of the geotechnical problem analysed may lead to gross errors. This in turn may result in either structure failure or not economical design. The proper choice of the constitutive model and the optimal evaluation of its parameters is not simple. Evidence to that fact has been given by the numerous publications about the variability of parameter values presented in Section 2.

One of the calibration methods, enabling estimation of any soil constitutive model parameters in such a way that the theoretical prediction possibly closely simulates the observed soil behaviour in a specific geotechnical case, is the Loading Path Method. As one of the local calibration procedures, it makes it possible to evaluate the parameter values in laboratory conditions, that is, with control of the states of stress and strain, giving at the same time results, which are much closer to global calibration than in the case of other local calibration techniques.

In this paper, an example of parametric identification with the use of the LPM was presented. It was applied to the elastic-perfectly plastic model with Coulomb-Mohr failure criterion in the case of a simple footing on a uniform cohesive subsoil. Genetic algorithms were used. The fitness function was based on the least square method. It was assumed that optimal was such a set of parameters, for which the difference between the theoretical response path at the chosen point of the subsoil and the experimental response path would be the smallest. Due to the fact that an exploitation state was analysed, it was impossible to estimate optimum values of cohesion and internal angle of friction. The optimal values of Young modulus and Poisson's ratio turned out to be smaller than suggested by the Polish Standard PN-81/B-03020. Additionally, fitting of the theoretical response path with the use of the optimum parameter values was even 4 times better than when the standard parameter values were used. This proved that the method was effective in the case analysed.

\section{ACKNOWLEDGEMENTS}

The experimental response paths presented in this paper were obtained by the author as a result of triaxial tests carried out in the laboratories of University of Bristol (Bristol, UK) and University of Massachussetts (Amherst, USA). The research was financed by the Ministry of Science and Higher Education as a "supervisor"s grant' N N506 368834 and by the Kosciuszko Foundation. 


\section{LITERATURE}

[1] Al-Tabbaa A., Muir Wood D., An experimentally based 'bubble' model for clay, Numerical Methods in Geomechanics NUMOG III (eds. S. Pietruszczak and G.N. Pande), Elsevier Applied Science, London, 1989, 91-99.

[2] Al-TabBaA A., Permeability and stress-strain response of speswhite kaolin, $\mathrm{PhD}$ thesis, University of Cambridge, 1987.

[3] AtKinson J.H., RichaRdSOn D., STALLEBRASS S.E., Effect of recent stress history on the stiffness of overconsolidated soil, Geotechnique, 40, No. 4, 1990, 531-540.

[4] AtKinson J.H., The deformation of undisturbed London Clay, $\mathrm{PhD}$ thesis, University of London, 1973.

[5] BJERRUM L., LO K.Y., Effect of aging on the shear-strength properties of a normally consolidated clay, Geotechnique, 13, No. 2, 1963, 147-157.

[6] Bouazza A., Van Impe W.F., Haegeman W., Some mechanical properties of reconstituted Boom clay, Geotechnical and Geological Engineering, 14, 1996, 341-352.

[7] BuRLAND J.B., On the compressibility and shear strength of natural clays, Geotechnique, 40, No. 3, 1990, 329-378.

[8] Burland J.B., Ninth Laurits Bjerrum Memorial Lecture: "Small is beautiful" - the stiffness of soils at small strains, Canadian Geotechnical Journal, 26, 1989, 499-516.

[9] ButTERFIELD R., A natural compression law for soils (an advance on e-log p'), Geotechnique, 29, 1979, 469-480.

[10] ChU J., GAN C.L., Effect of void ratio on K0 of loose sand, Geotechnique, 54(4), 2004, 285-288.

[11] CoOp M.R., AtKinson J.H., TAYlor R.N., Strength and stiffness of structured and unstructured soils, Proceedings of the 11th European Conference on Soil Mechanics and Foundation Engineering, Danish Geotechnical Society, Bulletin 11, Copenhagen 1995, Vol. 1, 55-62.

[12] COTECCHIA F., ChANDLER R.J., The influence of structure on the pre-failure behaviour of a natural clay, Geotechnique, 47, No. 3, 1997, 523-544.

[13] Cotecchia F., The effects of structure on the properties of an Italian Pleistogene clay, $\mathrm{PhD}$ thesis, University of London, 1996.

[14] CoulomB C.A., Essai sur une application des regeles de maximis \& minimis a quelques problemes de statique relatifs a l'architecture, Mem. de Math. et de Phys., presentes a l'Acad. Roy. des Sci., 7, Paris, 1773, 343-382.

[15] Dafalias Y.F., Herrmann L.R., A generalized bounding surface constitutive model for clays, Application of Plasticity and Generalized Stress-Strain in Geotechnical Engineering, eds. R.N. Yong and E.T. Selig (Proc. of the Symposium on Limit Equilibrium, Plasticity and Generalized StressStation Applications in Geotechnical Engineering), ASCE, 1982, 78-95.

[16] DeSAI C.S., Nonlinear analyses using spline functions, J. Soil Mech. Found., ASCE, 97, SM10, 1971, 1461-1480.

[17] Drescher A., Bojanowski W., On the influence of stress path upon the mechanical properties of granular material, Arch. Inż. Ląd., 14, 3, 1968, 351-369.

[18] Duncan J.M., Chang C., Nonlinear analysis of stress and strain in soils, J. Soil Mech. Found., ASCE, 96, SM5, 1970, 1629-1653.

[19] GENS A., A state boundary surface for soils not obeying Rendulic's principle, Proc. 11th Int. Conf. on SMFE, San Francisco, Vol. 2, 1986, 473-476.

[20] GIBSON R.E., Some results concerning displacements and stresses in non-homogenous elastic halfspace, Geotechnique, 17, No. 1, 1967, 58-67.

[21] Graham J., Noonan M.L., Lew K.V., Yield states and stress-strain relationships in a natural plastic clay, Can. Geotech. J., 20, 1983, 502-516. 
[22] Gryczmański M., JASTRZĘBSKa M., STERnik K., One surface elastoplastic model of clay with strongly nonlinear anisotropc hardening - calibration and numerical implementation (in Polish), report: BK-254/RB-7/98, 1998, Silesian University of Technology, Gliwice.

[23] GRYCZMAŃSKI M., KowALSKA M., Evaluation of geotechnical parameters in modern laboratory tests accounting for loading paths, Studia Geotechnica et Mechanica, Vol. 29, No. 1-2, 2007, 47-54.

[24] GrYcZMański M., On calibration of soil constitutive models (in Polish), Zeszyty Naukowe Politechniki Śląskiej. Budownictwo, z. 80, 1995, 37-52.

[25] GRYCZMAŃski M., State of the art in modeling of soil behavior at small strains, Architecture Civil Engineering Environment, Vol. 2, No. 1, 2009, 61-80.

[26] GRYCZMAŃSKi M., Introduction to description of elastoplastic models of soil (in Polish), Studia z Zakresu Inżynierii, nr 40, PAN, Warszawa, 1995.

[27] HaRdin B.O., DRNEVICH V.P., Shear modulus and damping in soils: measurement and parameter effects, Journal of Soil Mechanics and Foundations Div. ASCE, Vol. 98, No. SM6, 1972, $603-623$.

[28] Hardin B.O., The nature of stress-strain behavior for soils, Proc. ASCE Geotechnical Division Specialty Conference on Earthquake Engineering and Soil Dynamics, Pasadena, 1978, 1, 3-90.

[29] Henkel D.J., Sowa V., The influence of stress history on the stress paths followed in undrained triaxial tests, Proc. ASTM Symp. Shear Testing of Soils, Ottawa, 1963, 280-291.

[30] Jamiolkowski M., Lo Presti D.C.F., Pallara O., Role of in-situ testing in geotechnical earthquake engineering, 3rd Int. Conf. on Recent Advances in Geotech. Earthquake Engng. and Soil Dynamics, 1995, State-of-the-Art Report, 7.3, 1523-1546.

[31] Jardine R.J., Fourie A.B., Maswoswe J., Burland J.B., Field and laboratory measurements of soil stiffness, Proc. 11th International Conference on Soil Mechanics and Foundation Engineering. San Francisco, Vol. 2, 1985, 511-514.

[32] Jardine R.J., Potts D.M., Fourie A.B., Burland J.B., Studies on the influence of non-linear stress-strain characteristics in soil-structure interaction, Geotechnique, 36, 1986, 377-396.

[33] Jardine R.J., Symes M.J., Burland J.B., The measurement of soil stiffness in the triaxial apparatus, Geotechnique, 34, No. 3, 1984, 323-340.

[34] JARDINE R.J., Some observations on the kinematic nature of soil stiffness, Soils and Foundations, 1992, Vol. 32, No. 2, Japanese Society of Soil Mechanics and Foundation Engineering, 111-124.

[35] JASTRZĘBSKA M., Investigations of the behaviour of cohesive soils subjected to cyclic loads in the range of small deformations (in Polish), Monograph. Zeszyty Naukowe Politechniki Śląskiej, Wydawnictwo Politechniki Śląskiej, Gliwice, 2010.

[36] JefFeries M.G., Shuttle D.A., Dilatancy In general Cambridge-type models, Geotechnique, 52(9), 2002, 625-638.

[37] Kamegai Y., Deformation characteristics of sands by plane strain compression tests, Master of Engineering Thesis, University of Tokyo, 1994 (in Japanese).

[38] Kawaguchi T., Mitachi T., Shibuya S., Drained and undrained elastic moduli of reconstituted clay, Proc. International Conference on Soil Mechanics and Geotechnical Engineering (16ICSMGE), Osaka, 2005.

[39] KowalsKa M., GRYCZMAŃSKi M., Role of the stress path method in the contemporary investigation for civil engineering purposes (in Polish), Zeszyty Naukowe Politechniki Białostockiej, Budownictwo, z. 28, t. 2, Białystok, 2006, 163-172.

[40] Kowalska M., Calibration of Modified Cam Clay Model with use of Loading Path Method and Genetic Algorithms, Proc. XVIII European Young Geotech. Eng. Conference, Ancona (Italy), 2007.

[41] KowalsKa M., Parametric identification of soil models in geotechnical problems (in Polish), $\mathrm{PhD}$ thesis, Silesian University of Technology, Gliwice, 2009.

[42] KowalsKa M., Calibration of soil models with stress path method (in Polish), Zeszyty Naukowe Politechniki Śląskiej, nr 1695, Wydawnictwo Politechniki Śląskiej, Gliwice, 2005, 195-202. 
[43] Kowalska M., Various aspects of parameters in geotechnics, Architecture Civil Engineering Environment, Vol. 3, No. 1, Gliwice 2010, 47-52.

[44] LADD C.C., Stress-strain modulus of clay in undrained shear, Journal of Soil Mechanics and Foundations Division. Proc. of ASCE, Vol. 90. No. SM5, 1964, 103-132.

[45] Lade P.V., Duncan J.M., Stress path dependent behaviour of cohesionless soil, J. Geotech. Eng., ASCE, 102, GT1, 1976, 51-68.

[46] LAMBe T.W., Methods of estimating settlement, Journal of Soil Mechanics and Foundations Division, Proc. of ASCE, Vol. 90. No. SM5, 1964, 43-67.

[47] LeLievre B., Wang B., Discussion on stress-probe experiments on saturated normally consolidated clay, Geotechnique, 20, No. 1, 1970, 38-56.

[48] Leroueil S., Vaughan P.R., The general and congruent effects of structure in natural soils and weak rocks, Geotechnique, 40, No. 3, 1990, 467-488.

[49] Lewin P.I., BuRland J.B., Stress-probe experiments on saturated normally consolidated clay, Geotechnique, 20, 1970, 461-463.

[50] MACCARINI M., A comparison of direct shear box tests with triaxial compression tests for a residual soil, Geotechnical and Geological Engineering, 11, 1993, 69-80.

[51] MC Dowell G.R., HaU K.W., A simple non-associated three surface kinematic hardening model, Géotechnique, 53(4), 2003, 433-437.

[52] Mitchell J.K., Soga K., Fundamentals of Soil Behaviour, 3rd ed., John Wiley \& Sons, New Jersey, 2005.

[53] MŁynarek Z., Gogolik S., Gryczmański M., Uliniarz R., Settlement analysis of a cylindrical tank based on CPTU and SDMT results, Proceedings of the 4th International Conference on Geotechnical and Geophysical Site Characterization (ISC-4), Porto de Galinhas, Brasil, 18-21 September 2012 .

[54] MŁynareK Z., WierZBicKi J., LONG M., Factors affecting CPTU and DMT characteristics in organic soils, Proc. of XIth Baltic Sea Geotechnical Conference, Vol. 1, Gdańsk, 2008, 407-417.

[55] MонR O., Welche Umstände bedingen die Elastizitätsgrenze und den Bruch eines Materiales? Zeitschrift des Vereines Deutscher Ingenieure, 44, 1900, 1-12.

[56] Мовото N., Shearing deformation of granular materials such as sand, Report, Department of Civil Engineering, Hachinohe Institute of Technology, Hachinohe, Aomori, Japan, 1980.

[57] MoXhay A.L., Tinsley R.D., SutTON J.A., Monitoring of soil stiffness during ground improvement using seismic surface waves, 2001, http://www.surfacewavesurveys.co.uk/downloads/GrdEngArticle.pdf (February 2012).

[58] Muir Wood D., Soil behaviour and critical state soil mechanics, Cambridge, Cambridge University Press, 1990.

[59] Newland P.L., An Experimental Study of the Stress Strain Characteristics of a "Wet" Clay and Their Relevance to Settlement Analysis, Technical Report No. 15, Commonwealth Scientific and Industrial Research Organization, Melbourne, Australia, 1970.

[60] PN-81/B-03020 Building soils. Foundation bases. Static calculation and design.

[61] POWER P.T., The use of electric cone penetrometer in the determination of the engineering properties of chalk, Proc. 2nd European Symposium on Penetration Testing, ESOPT-II, Amsterdam, Balkema Pub., Rotterdam, 2, 1982, 769-774.

[62] PuZRin A.M., BuRland J.B., Non-linear model of small-strain behaviour of soils, Geotechnique, 48, 1998, 217-233.

[63] Rendulic L., Relationship Between Void Ratio and Effective Principal Stresses for a Remolded Silty Clay, Proc. of 1st International Conference on Soil Mechanics and Foundation Engineering, Cambridge, Mass., Vol. 3, 1936, 48-51.

[64] Roscoe K.H., Burland J.B., On the generalized stress-strain behaviour of "wet clay", Engineering plasticity, eds. J. Heyman \& F.A. Leckie, Cambridge University Press, Cambridge, 1968, 535-609. 
[65] SAnetra U., PACZEŚNiowski K., Calculation of internal friction angle and rock coherence by means of the method tangent to the envelope of Mohr's circles in the form of a parabola (in Polish), Prace Naukowe GIG, Górnictwo i Środowisko, 2/2006, 23-34.

[66] Schnaid F., In Situ Testing in Geomechanics, London and New York, Taylor \& Francis, 2009.

[67] Schofield A.N., The "Mohr-Coulomb" error, Mechanics \& Geotechnique, ed. Luong, LMS Ecole Polytechnique, 1998, 19-27.

[68] Shibuya S., Assessing Structure of Aged Natural Sedimentary Clays, Soils and Foundations, 40, No. 3, 2000, 1-16.

[69] SimOns N.E., The stress path method of settlement analysis applied to London clay, Stress-strain behaviour of soils (ed. R.H.G. Parry), Proc. of Roscoe Memorial Symposium, Cambridge, 1971, 241-252.

[70] Smith P.R., Jardine R.J., Hight D.W., The yielding of Bothkennar clay, Geotechnique, 42, No. 2, 1992, 257-274.

[71] Som N.N., The effect of stress path on the deformation and consolidation of London clay, $\mathrm{PhD}$ thesis, University of London, 1968.

[72] Stallebrass S.E., TAYLOR R.N., The development and evaluation of a constitutive model for the prediction of ground movements in overconsolidated clay, Géotechnique, 47 (2), 1997, 235-253.

[73] Sukolrat J., Structure and destructuration of Bothkennar clay, $\mathrm{PhD}$ thesis, University of Bristol, 2006.

[74] ŚwidzińSKI W., Compaction-Liquefaction Mechanisms of Granular Soils (in Polish), IBW PAN, Gdańsk, 2006.

[75] TAtsuoka F., Ishihara K., Stress path and dilatancy performance of a sand, Proc. 8th ICSMFE, Moscow, Vol. 1, 1973, 419-424.

[76] Tatsuoka F., Santucci de Magistris F., Hayano K., Momoya Y., Koseki J., Some new aspects of time effects on the stress-strain behaviour of stiff materials, Keynote Lecture, Proc. 2nd Int. Conf. Geotechnics of Hard Soils and Soft Rocks, Balkema, Rotterdam, Vol. 3, 1998, 1285-1371.

[77] Tschuschke W., Cone penetration testing in mine tailings (in Polish), Monograph, Zeszyty Naukowe Politechniki Śląskiej, Wydawnictwo Politechniki Śląskiej, Gliwice, 2006.

[78] VAn EeKelen H.A.M., Isotropic Yield Surfaces in Three Dimensions for Use in Soil Mechanics, International Journal for Numerical and Analytical Methods in Geomechanics, Vol. 4, 1980, 89-101.

[79] Wanatowski D., Chu J., Static liquefaction of Sand in plane strain, Canadian Geotechnical Journal, 44, 2007, 299-313.

[80] WANatowski D., ChU J., Undrained behavior of Changi sand in triaxial and plane strain compression, Geomechanics and Geoengineering: An International Journal, Vol. 3, No. 2, June 2008, 85-96.

[81] WiŁun Z., An outline of geotechnical engineering (in Polish), Wydawnictwa Komunikacji i Łączności, Warszawa 1976.

[82] Yasin S.J.M., TATSuOKa F., Stress history-dependent deformation characteristics of dense sand in plane strain, Soils and Foundations, Vol. 40, No. 2, 2000, Japanese Geotechnical Society, 77-98.

[83] Yudhbir, Mathur S.K., Kuganathan V., Critical State Parameters, Journal of the Geotechnical Engineering Division, Proc. ASCE, Vol. 104, No. GT4, 1978, 497-501. 